\title{
Work in Progress: A Holistic Approach to the First-Year Engineering Experience
}

\section{Mr. Kevin J. Lindsay, University of North Carolina at Charlotte}

Kevin J. Lindsay Freshman Lecturer and Advisor; MAPS Program Director

B.S. in Aerospace Engineering, Embry-Riddle Aeronautical University, 1999 M.S. in Physics, Clemson University, 2003 MBA, Loyola University in Maryland, 2010

I came to UNC Charlotte's William States Lee College of Engineering from the Space Telescope Science Institute (STScI) in Baltimore, Maryland. My 10 years of experience at STScI culminated in my final duties as a Senior Research and Instrument Analyst, and were spent working on astrophysics research, astronomical data analysis, and space-based instrumentation characterization, calibration, and experimentation. While at STScI I focused the majority of my efforts as a member of the development team for the Hubble Legacy Archive (HLA), as a member of the Cosmic Origins Spectrograph (COS) pipeline and calibration teams, and as a member of the Operations Detector Laboratory (ODL), where I worked on the characterization of spaced-based CCD detectors. Now at UNC Charlotte, I have found new passion in the education, advising, and mentoring of undergraduate engineering students.

Mrs. Meg Harkins, University of North Carolina at Charlotte

Meg Harkins is an Associate Professor of Practice, Freshman Engineering Advisor and Director of the Engineering Freshman Learning Community at UNC Charlotte's William States Lee College of Engineering. She is a licensed Professional Engineer in Pennsylvania with a Bachelors of Science in Civil Engineering and a Masters of Science in Environmental Science both from Drexel University.

\section{Dr. Rachael Ohu, University of North Carolina at Charlotte \\ Mr. Sherman Mumford, University of North Carolina at Charlotte}

Sherman Mumford is a freshman academic advisor and lecturer in the Lee College of Engineering at the University of North Carolina at Charlotte. He serves as Associate Director of Engage ME!, a multicultural engineers' mentoring and support program for underrepresented students majoring in engineering technology and engineering disciplines.

Mr. Mumford, is an active member in the American Society for Engineering Education (ASEE), is a life member of the National Society of Black Engineers (NSBE), has served in local and regional volunteer leadership roles in the Society of Manufacturing Engineers (SME) and the Institute of Industrial Engineers (IIE). He regularly advocates for science, technology, engineering and mathematics (STEM) education by serving on advisory boards, performing outreach and volunteering with youth organizations.

Mr. Mumford earned his bachelor's degree in Engineering Technology from UNC Charlotte, where he was a Ronald McNair Scholar; and earned his master's degree in Engineering Management from Eastern Michigan University. Prior to employment in higher education, Mr. Mumford worked in manufacturing operations and integrated product development within the commercial vehicles and aerospace and defense industries for three Fortune 500 Companies. His professional achievements include being certified as a manufacturing engineer, quality engineer and enterprise integrator. He has also received global quality achievement awards for process innovation and project execution.

\section{Mrs. Linda A Thurman, University of North Carolina at Charlotte}

Ms. Thurman, a Chicago native, earned her B.S. in Psychology from Western Illinois University and her M.A. in Industrial/Organizational Psychology from Roosevelt University. Moving to Charlotte in 1995, Ms. Thurman continued to work in the IT and Engineering recruiting field and then made a career change in 1999 to work in Higher Ed. She has worked for over 20 years at UNC Charlotte and currently serves as the Director for Student Professional Development and Employer Relations for the William States Lee College of Engineering. In March 2010, Ms. Thurman was appointed by the governor (and reappointed 
in 2015) to serve on the NC Board of Examiners for Engineers and Surveyors as the public member and her term expired Dec. 2019. She was the first public member to serve as the NC board chair (2018) . She is also heavily involved as an ASEE-CIPD Board member and in 2019 she was elected to be CIEC Treasurer and the Assistant PIC V. Ms. Thurman is also member of the WiMfg national and NC Chapter and SoACE and NCACE. 


\section{Work in Progress: A Holistic Approach to the First-Year Engineering Experience}

\section{Introduction}

The University of North Carolina (UNC) at Charlotte is North Carolina's urban research university. The William States Lee College of Engineering (COE) at UNC Charlotte maintains five departments with seven undergraduate degree programs. Within the COE, the primary goals of the freshmen student-focused Office of Student Development and Success (OSDS) are to improve retention and graduation rates by successfully guiding freshmen students through the transition experienced in their first year. OSDS works to connect and immerse freshmen students into the COE, and UNC Charlotte as a whole, in pursuit of achieving these goals. Faculty and staff in OSDS have observed that the development of personal connections for freshmen students within their new academic environment and home, can significantly ease their transition, while providing numerous opportunities to help them establish personal independence. Independence develops as freshmen students' step through the process of creating personalized support structures away from home. An apparent high level of intrinsic motivation to develop a personalized support structure forges academic ownership for a student, and works to establish a sense of pride for their choice of academic path and future profession. A student's willingness to adopt and follow this process through their first year, in many cases, will determine whether they are able to successfully transition and become independent learners, problem solvers, and young professionals within this unfamiliar context.

For the fall 2019 semester, approximately $27 \%$ of freshmen students in the COE were underrepresented minorities, as compared to an average $39 \%$ for all engineering program enrollment in the United States. Additionally, for the fall 2019 semester, only $13 \%$ of freshmen students in the COE were women, as compared to an average $26 \%$ for all engineering program enrollment in the United States [1]. The increase in variability of the new student higher education experience, and the goals of the COE, have led to the creation of new freshmen student support programs. Within OSDS, this has created an evolving partnership between new and existing freshmen student support programs to work toward optimizing student outreach, community connection, and ease of transition. The primary goal of this outreach effort is to maximize inclusivity and connection by providing a comprehensive set of resources for all students.

\section{Experimental Project Approach}

New COE student support programs have been developed by OSDS in the past three years to improve the academic success and retention of freshmen underrepresented minority and women students. These programs complement an array of preexisting OSDS programs whose broader purpose is to improve the academic success and retention of all freshmen COE students. The coalescence of new and old COE freshmen student support programs continues to evolve, with the goal of providing a holistic approach for reaching underrepresented minority and women students, and connecting them with their new academic and professional communities. 
This paper will focus on four Freshmen Student Support Programs, all of which will be quantitatively evaluated based on academic performance (GPA), and community connection (one-year retention) as seen in the Results and Discussion section. These programs are a combination of new and old initiatives whose mutual support lays the foundation for the holistic approach to student support that OSDS is striving to achieve. These programs include:

- Engage ME! (Multicultural Engineers)

- WE Engage! (Women in Engineering)

- Maximizing Academic and Professional Success (MAPS) Coaching and Mentoring

- Engineering Freshman Learning Community (EFLC)

Regular, consistent assessment and evaluation of academic success and retention metrics through these initiatives will allow us to narrow the strategic focus of each program to develop a common set of complimentary best practices. Metrics currently assessed for new underrepresented minority and women students participating in these programs, include their academic performance (GPA), and community connection (one-year retention). As shown in the Results and Discussion section, new underrepresented minority and women students who have participated in two or more OSDS Freshmen Student Support Programs during fall 2019 are evaluated based on these metrics. These results are then compared to freshmen students who participated in fewer than two COE freshmen student success programs. New Freshman Student Support Activities and Academic, Career, and Professional Development Activities are discussed in the Appendix to provide a comprehensive overview of all freshmen student support activities facilitated by OSDS.

\section{History of Freshmen Student Support Programs}

Going on 20 years, MAPS and the EFLC are the longest running student support programs developed by OSDS. The MAPS Program exists to increase the retention and academic performance of all students who are pursuing a COE degree. Although MAPS was originally developed and implemented through National Science Foundation (NSF) funding, it is now fully funded by the University as a key component of the Southern Association of Colleges and Schools (SACS) Quality Enhancement Plan (QEP), known as Prospect For Success (PFS). PFS is designed to foster academic engagement through three specific learning outcomes:

Commitment to Success, Inquiry, and Cultural Awareness. For more information regarding PFS learning outcomes, please see: https://prospect.uncc.edu/.

MAPS serves as indoctrination for new COE students to learn, understand, and establish personal connections to academic success and professional development strategies and campuswide resources, networking opportunities, and organizations. The program structure is divided into two peer-led components: (1) transition, academic, and professional development coaching and (2) Supplemental Instruction (SI) for selected COE gateway courses. The coaching program has evolved based on experiences and feedback from key stakeholders, leading to the continuous development of new strategies for improving participant satisfaction, academic and professional success, and retention. These enhancements have made a positive impact based on regular assessment results, which include overwhelmingly positive student participant feedback. Changes to the program continue to be made based on student participant needs and interests, 
with the expectation that they will continue to enrich and enhance their academic and professional experience.

The EFLC offers a unique college residential living experience through a holistic and integrated approach to the freshmen experience, and is designed to facilitate students' transition into the College and University communities. The program started in 2002 with 60 students, and quickly grew to capacity at 220 students, or approximately one third of the entering COE class. The EFLC is also an integral component of UNC Charlotte's PFS program. The EFLC is a twosemester, residential program for new COE freshmen students. Housed on campus in Hawthorn Hall, the EFLC combines the resources of both Student and Academic Affairs to support the goals of increasing one-year retention and academic performance, measured through GPA, graduation rates, and student satisfaction. The EFLC philosophy follows that these goals can be accomplished by building a sense of community, developing incoming freshmen into engineering students and providing opportunities for them to learn about their academic path and future profession. For more information regarding the curriculum and program structure of the EFLC, please visit: https://osds.uncc.edu/freshman-learning-community/overview.

Engage ME! in 2017, and WE Engage! in 2019, were developed to complement existing freshmen student support programs, with a focus on specific target populations whose numbers have been historically low relative to the larger university population and surrounding areas. Engage ME! is a diversity and inclusion program developed to recruit, retain, and graduate multicultural COE students. While open to all students, Engage ME! emphasizes engagement with African American, Hispanic/Latino and Native American students for personal, academic, and professional development. Although the UNC Charlotte student body reflects the diversity of our community, the same cannot be said for the COE. Underrepresented students from ethnic and racial minorities account for $41 \%$ of the University student body, but only $29 \%$ within the COE.

The goals of the Engage ME! program are to build a strong community of engineering students, facilitate student social and professional networking, foster academic and professional development, and position students to recognize and seize opportunities for success. Engage $\mathrm{ME}$ ! has partnered with campus and college resources such as the University Center for Academic Excellence, the University Career Center, the Office of Academic Diversity and Inclusion, the Office of Identity, Equity and Engagement, and the Office of Student Development and Success to better achieve these goals.

WE Engage! was developed to foster camaraderie and confidence in our women engineering students, by creating a tight knit community, and providing opportunities for networking and engagement. WE Engage! seeks to promote the development of COE women through the implementation of programs that enhance their recruitment, retention, and graduation rates. WE Engage! focuses on the academic success, professional development, and career growth of all COE women.

The Student Experience in Freshmen Student Support Programs 
Each of the four Freshmen Student Support Programs strives to be mutually supportive and complimentary, and in doing so has developed their own unique student experience. The focus herein will be on the current manifestation of the student experience as implemented for fall 2019. During fall 2019, 475 new COE students participated in the MAPS Program, distributed across 45 weekly sessions. This includes approximately $70 \%$ of the incoming freshman class. Each session had between 10 and 12 students facilitated by two upper-class COE students. Sessions began the second week of classes, and met approximately weekly for 10 weeks. Sessions cover a combination of relational and educational theme components. Throughout the 10 weeks, students are afforded the opportunity to develop friendships with their fellow session participants and coaches, in addition to taking part in various academic and professional development-based topic discussions. These topics are scheduled to coincide with various course related activities, and campus related events to provide students with an opportunity to practice what they learn. Topics include, effective workload management, networking, resume development, job hunting, study and exam preparation, mid-term assessment, team development, leadership, ethics, inquiry and resourcefulness, and future planning.

MAPS has shown, based on both quantitative and qualitative measures, that by adopting a philosophy of continuous improvement utilizing stakeholder insights and experiences, program growth can be achieved while improving upon measures of participant satisfaction, academic and professional success, and retention. Based on fall 2019 one-year retention and academic performance statistics, underrepresented minority students who actively participated in MAPS, earned an average GPA of 3.2, and were $28 \%$ more likely to be retained in the College after their first year. Those who did not participate in MAPS earned an average GPA of 2.7. Women students who actively participated in MAPS, earned an average GPA of 3.4, and were $18 \%$ more likely to be retained in the College after their first year. Those who did not participate in MAPS earned an average GPA of 2.8. For more information regarding the curriculum and program structure of the MAPS Program, please visit: https://osds.uncc.edu/maps-program/mapsprogram-brochure.

Space in the Hawthorn Residence Hall was designed to enhance student-to-student interactions and engagement for EFLC students. As of fall 2019, lounges are equipped with whiteboards and tables to encourage group study and team work. A classroom located in the basement is used for workshops, classes, and special events. The basement also houses the Creativity Lab, equipped with 3D printers, a laser cutter, and robotics equipment. Multiple design challenges are promoted each semester to encourage students to use the Creativity Lab and its resources to be hands-on problem solvers, as they work to complete the heavily theoretical courses of the first year.

EFLC survey results are used to continuously improve the program. Students typically enjoy living, studying, and socializing together. They perceive benefits of engaging with faculty and peers both in- and out-of-class. The strong bonds made in the EFLC frequently continue throughout their undergraduate career and after graduation. Quantitative analysis of the effect of EFLC participation shows equal first semester GPA, but slightly increased 4-year and 6-year graduation rates, over their non-EFLC counterparts. 
There were 42 registered Engage ME! program participants during fall 2019. Between 4 and 25 of the program participants were involved in four separate program sponsored events. These included a COE sponsored social gathering, a mentoring meet and greet, Co-op networking, and Convocation day welcome events. Industry supporters have been eager to increase their involvement with Engage ME!, as their support and resources provide a clear benefit to the program. Additionally, over the past year Engage ME! has achieved the following goals:

- Provide new COE students with opportunities to critically explore the engineered world we live in and engage in transformative learning experiences.

- Made strides to find its audience within the student community.

- Guide underrepresented minority engineering students to actively participate in organizations to facilitate personal network and community development, and simultaneously provide opportunities for skill development to ease the freshman transition.

- Provide support to student engineering organizations such as the Society of Hispanic Professional Engineers (SHPE) and the National Society of Black Engineers (NSBE).

- Provide professional mentoring for students coordinated with regional industries and government agencies that employ, or support, professional engineers.

The first program event for WE Engage! of fall 2019 was attended by five upper-class women COE students. They spent a Saturday morning working together at the University's Venture Team Challenge course. There they got to know women in other engineering disciplines and worked together to solve timed activities on a low ropes course. The outcome was gratifying not only did they all want to participate in a networking opportunity in the spring semester, but they also took the opportunity to continue their time together by going to lunch afterwards as a group.

Focus groups and biweekly meetings for new $\mathrm{COE}$ women students have been incorporated into the basic structure of the program. Similarly, study groups, which began in preparation of final exams during fall 2019 have been added. A new initiative under development includes a series of community development workshops. Challenges encountered through these endeavors include social media outreach, fundraising, and student acceptance and participation in events.

\section{Results and Discussion}

The initial implementation, or continuation of new student support programs have yielded positive results. The preliminary outcomes of these programs have been quantitatively evaluated, and will be evaluated qualitatively in the future. It is expected that future enhancements will capitalize on the unique nature of each program, while working to fill gaps to optimize the comprehensive support structure that OSDS strives to provide for all new students. Based on initial academic performance, assessment and evaluation for new freshman participating in two or more freshmen student success programs results in an average increase in GPA of 0.26. Similarly, for underrepresented minority and women students, participation in two or more student success programs, relative to participation in one or fewer student success programs, results in an average increase in GPA of 0.25 and 0.28 , respectively. It is important to note that participation in any student support program mentioned is completely voluntary for those students involved. 
Table 1: Fall 2019 OSDS Freshmen Support Program College of Engineering New Freshman GPA

\begin{tabular}{|c|c|c|c|c|}
\hline \multirow{2}{*}{ Student Category } & \multicolumn{3}{|l|}{ Participation: $\geq 2$ Programs } & \multicolumn{2}{|c|}{ Participation: $\leq 1$ Program } \\
\cline { 2 - 5 } & $\mathrm{n}$ & $\begin{array}{c}\text { 1st Term GPA } \\
\text { (mean) }\end{array}$ & $\mathrm{n}$ & $\begin{array}{c}\text { 1st Term GPA } \\
\text { (mean) }\end{array}$ \\
\hline $\begin{array}{c}\text { Underrepresented } \\
\text { Minority }\end{array}$ & 30 & 3.23 & 128 & 2.98 \\
\hline White & 127 & 3.25 & 265 & 2.99 \\
\hline Female & 18 & 3.47 & 54 & 3.19 \\
\hline $\begin{array}{c}\text { Female } \\
\text { Underrepresented } \\
\text { Minority }\end{array}$ & 5 & 3.38 & 26 & 3.19 \\
\hline Female White & 13 & 3.51 & 28 & 3.19 \\
\hline Male & 143 & 3.21 & 351 & 2.95 \\
\hline $\begin{array}{c}\text { Male } \\
\text { Underrepresented } \\
\text { Minority }\end{array}$ & 25 & 3.20 & 102 & 2.93 \\
\hline Male White & 114 & 3.22 & 237 & 2.97 \\
\hline
\end{tabular}

For the preliminary analysis and evaluation of one-year retention data, only those students participating in EFLC and MAPS during the fall 2018 semester will be taken into consideration. This is due to the fact that the Engage ME! and WE Engage! programs, still in their infancy in fall 2018, had low levels of student participation. The table below shows that for new freshman participating in two freshmen student support programs, results in an average increase in oneyear retention for the COE, and the University as a whole, of $21.6 \%$ and $10.6 \%$, respectively. Similarly, for underrepresented minority and women students, participation in two or more student success programs, relative to participation in one or fewer student success programs, resulted in an increase in one-year student retention of $35.4 \%$ and $5.9 \%$, respectively. 
Table 2: Fall 2018 OSDS Freshmen Support Program College of Engineering New Freshman One-Year Retention

\begin{tabular}{|c|cc|c|c|c|c|c|c|}
\hline & \multicolumn{2}{|c|}{$\begin{array}{c}\text { Participation: } \\
\geq 2 \text { Programs }\end{array}$} & \multicolumn{2}{|c|}{$\begin{array}{c}\text { Participation: } \\
\leq 1 \text { Program }\end{array}$} & \multicolumn{2}{|c|}{$\begin{array}{c}\text { Participation: } \\
\geq 2 \text { Programs }\end{array}$} & \multicolumn{2}{|c|}{$\begin{array}{c}\text { Participation: } \\
\leq 1 \text { Program }\end{array}$} \\
\cline { 2 - 11 } Student Category & $\begin{array}{c}\text { \% Retained } \\
\text { in College } \\
\text { of } \\
\text { Engineering }\end{array}$ & $\mathrm{n}$ & $\begin{array}{c}\% \text { Retained } \\
\text { in College } \\
\text { of } \\
\text { Engineering }\end{array}$ & $\mathrm{n}$ & $\begin{array}{c}\% \text { Retained } \\
\text { in } \\
\text { University }\end{array}$ & $\mathrm{n}$ & $\begin{array}{c}\% \text { Retained } \\
\text { in } \\
\text { University }\end{array}$ \\
\hline $\begin{array}{c}\text { Underrepresented } \\
\text { Minority }\end{array}$ & 29 & $93.10 \%$ & 130 & $57.69 \%$ & 29 & $93.10 \%$ & 130 & $78.46 \%$ \\
\hline White & 117 & $78.63 \%$ & 320 & $59.69 \%$ & 117 & $91.45 \%$ & 320 & $79.38 \%$ \\
\hline Female & 15 & $80.00 \%$ & 54 & $74.07 \%$ & 15 & $93.33 \%$ & 54 & $90.74 \%$ \\
\hline $\begin{array}{c}\text { Female } \\
\text { Underrepresented } \\
\text { Minority }\end{array}$ & 3 & $100.00 \%$ & 22 & $63.64 \%$ & 3 & $100.00 \%$ & 22 & $81.82 \%$ \\
\hline Female White & 12 & $75.00 \%$ & 32 & $81.25 \%$ & 12 & $91.67 \%$ & 32 & $96.88 \%$ \\
\hline Male & 131 & $81.68 \%$ & 396 & $57.07 \%$ & 131 & $91.60 \%$ & 396 & $77.53 \%$ \\
\hline $\begin{array}{c}\text { Male } \\
\text { Underrepresented } \\
\text { Minority }\end{array}$ & 26 & $92.31 \%$ & 108 & $56.48 \%$ & 26 & $92.31 \%$ & 108 & $77.78 \%$ \\
\hline Male White & 105 & $79.05 \%$ & 288 & $57.29 \%$ & 105 & $91.43 \%$ & 288 & $77.43 \%$ \\
\hline
\end{tabular}

Preliminary results indicate that a holistic approach to the freshmen experience of COE students aids in their transition into the College, and the larger UNC Charlotte communities. Participation in two or more OSDS academic support programs enhances students' academic performance and retention. Women and students from underrepresented ethnic groups participating in two or more programs show increases in GPA. Efforts will continue to increase participation of underrepresented minority groups and women in OSDS academic success programs. Additional assessment will be conducted of the Engage ME! and WE Engage! programs to determine their impact on student academic performance and community connection. 


\section{Appendix}

Appendix I

New Freshman Student Support Activities

New Freshman Advising

All new COE freshmen are centrally advised in OSDS. The advising team is composed of the Director of Recruiting and Freshman Advising, and faculty who teach the Introduction to Engineering and Engineering Technology courses, many of whom also direct freshmen student support programs. Freshmen advisors assist students with major options and course selection. They monitor student progress and verify that pre- and co-requisites are satisfied, and strategically intervene at four weeks, midterm, and the end of the semester after grades post. Advisors also make referrals to other department programs on campus that provide academic success resources, including the University Center for Academic Excellence, Writing Resource Center, Center for Counseling and Psychological Services, University Career Center, and Financial Aid. Academic advising is an integral component of UNC Charlotte's PFS program.

OSDS advises approximately 700 new and continuing freshmen each academic year. COE freshmen advising begins at admission. Students are expected to complete an online math review module as a prerequisite to their first engineering course, and are encouraged to review an online Orientation BootCamp, which introduces them to the academic success strategies and university resources. At orientation, new freshmen meet OSDS staff and student workers. Upper-class engineering student workers assist and answer questions during orientation, and remain in communication with new freshmen throughout the summer using social media and forums in the online BootCamp.

The Introduction to Engineering and Engineering Technology and Engineering Transition for Freshmen Students Courses

The Introduction to Engineering, Engineering Technology, and the Engineering Transition for Freshmen Students courses, are designed to introduce freshmen COE students to the various disciplines and practices in their future professions. This is done with the goal of providing encouragement and developing enthusiasm for new COE student's future opportunities. These courses work to provide new COE students with a glimpse of some of the tools, techniques, and skills of their future profession. They are all taught by OSDS faculty, who have themselves spent a significant amount of time working as engineers or engineering technologists in industry, and who strive to provide a real-world feel to each class meeting. Each of these three classes are also designated PFS freshman courses.

As the Engineering Transition for Freshmen Students seminar is a foundational, lead-in, course for Introduction to Engineering and Introduction to Engineering Technology, several preliminary topics are covered. This course was created for new freshmen who do not qualify for either the Introduction to Engineering or Introduction to Engineering Technology courses, typically based on starting math level. This course provides new freshman with a formal environment to learn about their major, career path, and to connect with their college, which otherwise would not be possible for this population during this critical period of transition in their first semester. The 
course is taught by engineering faculty, and topics include problem solving, academic majors and career paths in engineering and engineering technology, study and organizational tools, basic professional development skills and campus resource availability. Upon completion, students should be integrated into the COE community, and have developed a clearer understanding of their future academic and professional goals and career path options.

In the Introduction to Engineering course, students are exposed to engineering disciplines, the engineering design process, project management tools and techniques, multidisciplinary teamwork skills, academic success and professional development skills, communication skills, and general mathematical problem solving. In the Introduction to Engineering Technology course, students are exposed to Engineering Technology and Construction management disciplines, the engineering design process, academic success and professional development skills, communication skills, and general mathematical problem solving. For freshmen in the Introduction to Engineering or Engineering Technology courses, their understanding of the topics listed above, and through completion of a series of individual and team-based tasks and projects, they learn the fundamentals of what it means to be a successful Engineering or Engineering Technology student.

Appendix II

Academic, Career, and Professional Development Activities

\section{Day of Convocation}

The first day of classes each fall semester is the Day of New Student Convocation. This day is dedicated to welcoming and introducing new undergraduate students to the COE and to the larger University community. The day begins with new COE students gathering with faculty, staff, and department administration for the College Dean's welcome. As a class, new students then parade across campus to attend the New Student Convocation ceremony, which is structured and designed to educate new students on UNC Charlotte's history, mission, values and academic expectations. This ceremony is followed by a class lunch, and then opportunities to network and connect with other students, faculty and staff through a combination of departmental tours and freshman resource engagement activities. During the afternoon activities, all OSDS freshmen student support programs come together in a small resource fair. This is an opportunity for freshmen students to meet freshmen course COE professors, freshmen advisors and upper-class COE students, while learning about student support programs, how they are connected, and what they can provide to further each students academic and professional success.

\section{The William States Lee College of Engineering Fall Picnic}

The COE's annual fall exploration, recruiting and networking picnic draws more than 1500 people each year. In fall 2019, more than 122 engineering companies participated in the event, and several conducted pre-event information sessions and post-event interviews. Some departments also hold program-specific career events. For example, companies whose work focuses more on the fields of Construction Management and Engineering Technology also participate in the annual fall Department of Engineering Technology and Construction Management, Construction Internship and Career Fair. The Department of Civil and 
Environmental Engineering hosts a sold-out annual Discover Civil Engineering event every spring.

These events are incredible opportunities for new COE students to explore engineering disciplines, to further develop communication and networking skills, and to gain invaluable experience. Freshmen spend time researching companies of interest, engaging in conversations with those companies, and observing upper-class student's interactions with employers. From these interactions, freshmen not only develop networking and communication skills, but also an understanding for what they can do to make themselves more marketable.

\section{Acknowledgement}

We would like to express our gratitude to all of our colleagues in the OSDS office for their contributions to the student success initiatives. We would particularly like to thank Dr. Cathy Blat for her unwavering support, and contributions toward the completion of this paper.

\section{References}

[1] J. Roy, "Engineering by the Numbers," ASEE.org [Online] Available: https://ira.asee.org/wpcontent/uploads/2019/07/2018-Engineering-by-Numbers-Engineering-Statistics-UPDATED15-July-2019.pdf. [Accessed September 13, 2019]. 